Journal of Behavioral Economics, VIII, 1 (Summer, 1979), 23-37. Reprinted in the Journal of Cultural Economics, Dec. 1980. Reprinted in Arnold Berleant, Aesthetics and Environment, Theme and Variations (Farnham, UK \& Burlington, VT: Ashgate, Publishing Ltd, 2005), pp. 123-132. ISBN 978-0754650775

\title{
SUBSIDIZATION OF ART AS SOCIAL POLICY
}

\begin{abstract}
The arts have always been integrated into their larger culture, responding to shifts in taste and fashion and to changes in the social uses to which they have been put, as much as they have promoted those same changes. Even their alienation reflects a social influence. When this relation between society and the arts is recognized and affirmed, it can enhance both by rediscovering the human locus of perceptual meaning and by encouraging fuller social consciousness. An enlightened and imaginative program of subsidies would promote cultural evolution. And an inclusive conception of art and its social role can lead to their distinctive contribution to the physical and social shape of our environment.
\end{abstract}

Subsidy of the arts has arrived belatedly in this country as a matter of national policy and action. Only in recent years, mainly since 1965 when the National Endowment for the Arts (NEA) was established, has the subsidy of art in this country become an official policy. For nearly the entire two centuries of our existence as a nation, the arts have depended on a combination of private philanthropy and individual sacrifice to carry on their various activities. The fact that they have developed and flourished demonstrates that in the arts, as elsewhere, our country has people who possess extraordinary initiative, dedication, talent, and a capacity for self-sacrifice.

Yet this policy, like any policy, has encouraged some forms of activity and not others. It has produced a free enterprise economy of the arts, bestowing rewards for successful entrepreneurship, for anticipating and supplying fashionable tastes. In general this has meant support for art that could either magnetize a mass audience, like film or pop music, or that could attract audiences whose smaller numbers were counterbalanced by sufficient personal affluence to support major events of high culture, such as opera, theater, and concerts of music and dance, usually with a major performer as the principal drawing power. Even here, the cost of large organizations was never met by box office receipts, and the private patron became the sustaining force in such endeavors. This was a system that bred the entrepreneur, the impresario, and the star, and also a supporting cast of ragged artists, who often could sustain themselves only through alternative employment, and who subsidized the arts through their acceptance of a minimal income.

In recent years this has changed, largely through the growth of collective action and support. Subscription series have created regular audiences and assured the financing of seasonal programming. Guaranteed employment for full seasons and professional associations that have taken the economic leadership in bargaining have made the condition of performing artists somewhat more stable. Efforts are being made to extend the royalty system to creative artists not previously covered by it, such as painters and sculptors. And with federal subsidies, most notably through the NEA and its correlative state councils, along with increased private foundation and corporate support, the 
condition of artists and the arts has begun to change in significant ways. Indeed, there appears to be a proliferation of regional art activities in the form of groups, institutions, performances, workshops, lectures and conferences. We would appear to stand at the threshold of a period of great cultural awakening.

There is no doubt that the developments of the past fifteen years signify a major shift in the attitude toward the arts of the general public and major institutions in this country. We seem finally to have joined those nations who regard their life of high culture as a major resource and one that warrants regular, sustaining support. In observing the change in national priorities that recognizes "that a high civilization must not limit its efforts to science and technology alone but must give full value and support to the other great branches of man's scholarly and cultural activity" (7), as the legislation that established the National Endowments for the Arts and Humanities stated, I have naught but praise for a broad and inclusive cultural effort. It might be useful, however, to view this emerging concern for the arts with a fresh and wider vision so that we may better assess its significance and assist its efforts.

Support for the arts seems clearly directed toward the broad range of objects and events we commonly agree to call art--opera, ballet, theater, painting, music, sculpture, and architecture, among others. At times we broaden our view to include those crafts and skills that clearly embody similar principles and values--ceramics, glass blowing, cabinetry, leatherwork, furniture design, and more recently such things as industrial design. Wide though such a range of arts may be, a view of social support that is directed exclusively toward them suffers from a major limitation. Its purpose is to support the production and preservation of objects and, in the performing arts, the presentation of events. That we narrow our range and restrict our focus to such easily identifiable objects seems both necessary and obvious. Is not this what art is, and can we not mark the great ages of cultural bloom by the plays of Sophocles and Shakespeare, the sculpture of. Phidias and Michelangelo, the painting of Leonardo and Rembrandt, the music of Bach and Beethoven?

Yet the authors of these works did not appear spontaneously and unpredictably; such remarkable figures emerge as part of an organic rather than a magical process. Art grows and ripens as a culture matures. Not that it comes as the last stage of cultural development, for in some form or other the arts pervade every human society and at every level of development. Yet the roots of the most lofty achievements in art penetrate deep into the soil of their entire civilization and are nourished by its cultural fertility and its social climate. An artistic culture, then, does not consist in a collection of objects; it is rather the very atmosphere of thought, interest, and activity from which those objects emerge. To put it more directly, the art works we value are but the more noticeable and identifiable features of a broad and inclusive cultural process. We should direct our efforts, therefore, to enriching such a process and not only to magnifying the signs of its success.

The original Greek usage of our central terms suggests this interpretation. 'Art ' initially referred to the skill in making or doing things, and 'aesthetic' concerned our perception of interesting objects by both feeling and the senses. Such breadth of significance suggests an inclusiveness that broadens art to embrace all skillful activity, and its appreciative aspect to involve a full range of response. It is only in the recent history of the arts that invidious distinctions have been drawn between fine and practical art, between creating and responding to art, between appreciating and participating in 
art, between perceptual delight and practical function. Such divisions are unfortunate, for they isolate phases of a cultural process that merge in practice as inseparable parts of the life of a total culture, and lead to the erection of barriers between these functionally continuous activities. This development of specialized artistic function parallels a similar compartmentalization of other activities in complex modern societies. While both render easier the technical mastery that industrial technology requires, they lead to the fragmentation of the lives of individuals and their collective culture.

For all the intensity of achievement that the specialization of work produces, it seems inevitably to promote a poverty of imagination at the same time as it expands the level of subsistence. To achieve a humanized culture in an industrial civilization requires us deliberately to foster interchange and connectedness among the divided domains of social life so that its qualities and meanings attain greater integration. The arts, in fact, have never left craft technology far behind, and even when they employ sophisticated industrial skills, materials, and equipment, they do so mostly on a small scale. In this case, such a separation of functions leads to a narrowing of the range of aesthetic involve-ment and response. The general problem, then, is to redirect modern social life in order to develop a breadth of deliberate awareness, both cognitive and perceptual, while still retaining the concentration of activity that the attainment of expertness requires. Here the arts hot only can benefit from such integration in their own right; they can serve as a model for the general culture as well.

The argument might be offered that whatever the original meaning of art and the aesthetic, that is no reason to observe it today, and to insist otherwise would be to entangle oneself in a genetic fallacy. Surely meanings evolve to respond to altered conditions and needs, and we should be prepared to adapt to them. In this case, an industrial society can only survive when its complex and arcane workings are guided by the highly trained professional. Indeed, it is an identifying trait of our advanced industrial civilization that the professional has displaced the worker in proportionate numbers as well as in importance. Similarly have the arts become more complex, created by exotic techniques under the guidance of a seemingly incomprehensible imagination. Such an art requires a specialization of appreciation to match that of creation, and the recent history of the arts has produced a corresponding evolution of their audience.

It is essential to realize, however, that the arts have always been integrated into their larger culture. They have responded to shifts in taste and fashion and to changes in the social uses to which they have been put as much as they have promoted those same changes. This was equally the case in medieval Christendom, Renaissance Italy, Elizabethan England, seventeenth century Holland, and Enlightenment France, as it was in classical Greece. Indeed, one could easily regard the progressive isolation of the arts in the past three-quarters of a century as an aberration in their social history. Yet it may be more accurate to see this phase of aesthetic alienation as accomplishing two purposes: it provided the ground for the identification and cultivation of an aesthetic sensibility as such, and at the same time it offered an independent place from which to launch an artistic critique of the threats to humanistic values contained in social changes during the past century and a half.

This is not the place to develop a case for the continuity and dependence of the arts on the total culture, although their entire history stands behind it. What is essential at our present stage of social development is to recognize and rearticulate this integration as a 
current cultural necessity. There is much to be gained by the diffusion and assimilation of the aesthetic in the wider culture, not just in the form of heightened sensibility and \$fuller social consciousness, but in the possibilities it offers for the rediscovery of the individual human locus of perceptual meaning in mass society and culture. Furthermore, an enlightened policy of subsidization of the arts should have such scope constantly in view, and regard the attainment of this goal as its principal mission.

Such a general claim as I have been making needs specifi- cation in order that we may see the concrete significance of a widened and integrated cultural aesthetic. Let me therefore propose as illustrations a number of areas that suggest the kinds of differences in practice that would follow from a broadened and enlightened policy of subsidization.

The standard form that urgings for artistic subsidy take consists in recounting the difficult straits in which major institu- tions of high art find themselves. Figures are cited that offer convincing evidence of the economic crisis that besets the leading symphony orchestras, opera companies, and museums. Careful argument and documentation (2) have generated a swell of public support for these institutions, and since the mid-sixties there has been an impressive and growing amount of subsidy provided by a full range of public and private sources. We have seen federal and state governments recognize that the arts are not just a source of private delectation but represent major social values that need to be encouraged and made secure from the constant threat of extinction. We have seen private foundations assume a catalytic role in artistic as well as other areas, giving financial encourage- ment to new ventures during their early period of organization and consolidation. The economic position of our major artistic institutions seems relatively assured.

This is not a sanguine situation, however, and on several counts. First, the dollar amount seems impressive until we see it in relation to costs and expenditures. One considers that great achievement has occurred when the major source of funding for the arts, the National Endowment for the Arts, has increased its appropriation from about $\$ 2,500,000$ when it began in 1966 to $\$ 85,000,000$ in 1977 . According to the 1977 Annual Report of the NEA, between 1965 and 1975 there occurred a burgeoning of cultural institutions: a doubling of professional orchestras, a quadrupling of resident professional theaters, a five-fold increase in the number of arts councils, and a sevenfold increase in the number of professional dance companies. Yet when spread across a nation of fifty states and 225 million people, there may be more sound here than substance. Indeed, the total expenditure for the arts by the NEA during its eleven-year history is just over $\$ 453,000,000$--hardly enough to provide every inhabitant of the United States with one free movie $(6,13)$. Private foundations are similarly limited in the quantity of their support. In 1974-1976 they donated somewhat over $\$ 180,000,000$ to the arts, only about 8 percent of all their grants (11). Businesses are allowed a maximum deduction of 5 percent of taxable income for charitable contributions, but in 1976 the average was 1 percent, provided by only 20 percent of the 1.7 million corporations in this country, and only a small percentage of this went to the arts (1). The rela- tive poverty of such subsidies becomes more evident when we recognize that in the mid-1960's, when the U.S. first began to offer significant financial support, western European countries subsidized from 65 percent to 90 percent of the costs of opera, theater, and concerts. At that time the Metropolitan Opera was obliged to cover 85 percent of its costs through ticket sales, and the rest through benefactions. Even today, with substantial public 
support, ticket prices still exclude all but the affluent. Moreover, European countries often subsidize initial publication costs for writers, poets, and composers by as much as 30 percent (5). Not being an economist, I have difficulty amassing the data for an elaborate statistical argument, but even such evidence as is readily available seems clear in its import.

But there is more to the situation than just support sharply limited in quantity. There is a deeper problem in the narrowness of its range. Awards tend to go only to established organizations and individuals, and considerations of safety and accountability take precedence over imagination and innovation. A review of the annual reports of the various programs of the NEA shows that even those grants that reach individual artists are paltry in sum--most commonly in the neighborhood of $\$ 2,000$, with rather larger grants going to some of the most highly recognized artists--amounts that in both cases are of a size that will make little financial difference in supporting artists at that stage in their careers when they are safe enough investments to justify receiving them.

Moreover the appointment of new chairmen of the NEA and NEH has provoked considerable public discussion of the policy guiding the disbursement of federal funds in these areas. Questions have been raised challenging the scope of federal subsidies, with some critics deploring support for "educationalists, audiences and amateurs as well" ( 3 , p. 72) as professional artists and scholars, and questioning a policy that encourages the broad distribution of funds over many levels of institutions involved in the arts and over a wide range of locations beyond the few great urban centers (10).

Yet the choice does not lie between elitism and populism; such an alternative embodies that unhappy disjunction between higher and lower art, high and popular culture that in practice has such limited historical credibility. It is indeed ironic that this elitism in art should coincide with the progressive democratization of world societies. The answer is clearly not a question of deciding which beggar should be given a crust, but rather in realizing that all contributions to the general enhancement of cultural values merit support and that such backing should be generous and sub-stantial. We must face in concrete terms the likelihood that an attack on the roots of poverty is as much a war on cultural poverty as on material want. An aesthetic penuriousness atrophies both sensibility and imagination as much as economic want debilitates health, and both persist in perpetuating themselves.

Related to this is the unfortunate tendency toward centralization in art as much as in industry. Indeed, even as industry has begun to distribute itself over a wider range of locations, art has continued to gravitate toward a few major centers and primarily toward New York. Moreover, even there the arts tend to be focused in a relatively few leading museums and cultural institutions. There is an interesting countermovement developing, however, in the direction of a healthy regionalism. Cities scattered throughout the country have begun to become regional hubs for artistic activitiesBAtlanta in the southeast, Seattle in the northwest, San Diego in the southwest, and Minneapolis in the north central, to name some of the more outstanding. Moreover, universities have assumed the role once held by the princely courts of the Renaissance as the locus of the arts. They have become seats of culture and patrons of artists, and have encouraged an important regionalism independent of the largest population and commercial concentrations. This is but a step toward the equitable access to every one of our cultural resources. Here we might emulate Europe, where even small cities often have their opera house, their theater, their symphony orchestra, and their art museum. 
In an effort at imitation, State Arts Councils have encouraged tours by opera, ballet, orchestra, and theater groups, and have begun to support local programs. Yet we have only begun to distribute access to our cultural hoards. A single shift in practice that would have powerful consequences, to mention but one area, would follow from a basic change in museum philosophy. Instead of regarding museums as treasure houses in which four-fifths of their great collections are buried in storage vaults, these hidden mines of cultural riches, representing social wealth amassed through centuries of civilization, could be loaned to local museums and exhibition halls, and placed in traveling exhibits sent throughout the villages, towns, and small cities of the country.

Artistic careers, likewise, need not be confined to the tiny number of people who, by a combination of outstanding talent, financial resources, personality traits, and the smiles of fickle fortune, are able to establish themselves successfully. There is much wasted talent that could contribute in a major way to extending cultural exposure and aesthetic experience by working at the level of the local community. The mass audience, which alone can support the super star, may have its place, although this can be challenged on grounds of aesthetic dilution and ineffectiveness. Cavernous halls and surging crowds are not the setting in which to discover the intimacy of art. There is rather a great need to engage art on a personal level. As books have replaced the lecture, recordings and television are capable of supplanting performances for the mass audience, overcoming the distance of time and place to create a certain real contact and warmth. Living events, on the other hand, should be on a scale proportionate to human persons, and smaller museums and auditoriums offer the proper balance. What is needed "is to humanize the aesthetic situation. A certain deprofessionalization would be a similar help, for at times the line between the professional and the amateur is drawn in economic terms and not in artistic ones. A local level of art activity can rest on talent and availability instead of on mass advertising and the finances and organization to secure it. Because the performance and the appreciation of the arts are inseparable, a far wider participation in both phases will breed both a more knowledgeable and responsive public and artistic results of unexpected quality.

In the light of my earlier observations on the integration of the arts with the larger culture, it may be in education that the richest opportunity exists for the aesthetic enlightenment of American society. It is in the formative years that perceptual and motor skills are most malleable, and indeed, as psychological research has suggested in certain cases, the very capacity to assimilate such experiences must be exercised at critical points in a child's development or it will never develop. What is needed is not simply exposure to the arts and educational programs to teach skills in them. More basic yet is the awakening of perceptual capacities which the arts have a singular ability to help us discover and extend. It is essential to realize that this is not a matter of cultural polish. It is a question of full human sensibility--perceptual awareness, sensitivity to people, an understanding of personal meanings, and the capacity for feeling. To attain this is not just a matter of introducing courses in the arts into the curriculum. It is one of assimilating the arts into the very fabric of the subjects presently taught, for by increasing their perceptual significance we enhance their meaning and improve our understanding. Communication skills, for example, involve not only grammar and speech but the language of gesture and image which dance, theater, photography, and film exploit most effectively. Social studies deal not only with matters of historical fact, political processes, and economic practices; they concern human freedom, fate, and 
fulfillment, which are no more eloquently exhibited than in literature, theater, painting, and poetry. Science and mathematics encompass more than fact and formula; they exhibit art in theory construction and involve orders of space, time, mass, structure, and volume whose perceptual dimensions are the frame and forms of the human environment, and are revealed in our engagement with sculpture and architecture. ${ }^{2}[$ Strong support for aesthetic education and numerous recommendations for accomplishing this have come from the Panel on the Arts, Education, and Americans, which recently published a comprehensive and resourceful study (8).

But the arts must not be seen only as an addendum to the curriculum. They represent, in their own right, the heart of human experience. No, they do more than represent it: they embody it. By teaching children to enter its world, the arts enter theirs and change it. Instead of an education that instructs children in a world of limitations, experience with art can promote heightened consciousness of their surroundings and creative outlets for their energies.

Finally, a broad and inclusive conception of art and its social role can lead to a distinctive, contribution of the arts to the physical and social shape of our environment. The arts develop in their practitioners highly sensitized perceptual abilities and a sharpened awareness of the sensory domain. Such skills lead to a distinct perspective and would make artists valuable collaborators with the disciplines that join together in the process of environmental planning. Yet artists are rarely if ever involved. An enlightened understanding of the social role of the arts would encourage the regular participation of aesthetic consultants in city and regional planning and in environmental studies. Construction and zoning regulations become policies that guide building decisions and practices. Yet they do more than set physical speci- fications. They are policies that shape our surroundings and create the conditions for human life and consciousness. Choices made in the planning process thus determine the kind of human world we inhabit. A conception of art as a social activity generating a communal setting acknowledges, then, that aesthetic experience makes a social contribution, a contribution toward the experience of full community.

A perspective on art and the aesthetic that welcomes the uniqueness of what they offer education, planning, and other social activities integrates art into the life of a society. It recognizes the formative influence of art on the pervasive qualities of a culture. On such a view a social goal emerges: the development and assimilation of an artistic-aesthetic component into the general culture of our society. As a social interest, this is an objective that requires social investment and support. To urge such backing. however, is not to placate special interest groups, for the arts are not a special interest but a general social one. Thus in supporting art we are not subsidizing art alone but the entire society, and through the arts assisting in the evolution of a distinctive American culture. In fact, "a period of efflorescence in the arts is apt to lead a cultural advance: it formulates a new way of feeling, and that is the beginning of a cultural age" $(4, \mathrm{p} .46)$.

This is no vacuous homily. Becoming conscious of the pervasiveness of the aesthetic in culture leads us to recognize that social support through an enlightened and imaginative program of subsidies is a necessary means of promoting cultural evolution. What is essential is that we broaden our economic parameters to incorporate aesthetic and more generally cultural values, and that we develop a new accounting system in the service of a "total economics." 
The British artist John Latham proposes substituting units of attention for monetary units, and the general level of awareness within a community and the increase of consciousness through time for the gross national product. Latham relates each unit of attraction to the number of people who are affected by an idea, the length of time it is influential, and the degree of awareness that it induces measured by a scale that moves from uncons- ciousness to most heightened awareness (12).

President Johnson's endorsement of the National Foundation on the Arts and the Humanities Act of 1965 proclaimed that by establishing such a foundation, "we follow the example of many other nations where government sympathy and support have helped to shape great and influential artistic traditions." [Statement by the President on the proposed National Foundation on the Arts and Humanities, March 10, 1965 (9, p. 273).]

What is necessary is a major recognition of the central importance of aesthetic awareness throughout American society and full social commitment to the support of the arts, understood broadly and inclusively. To accomplish this is an essential goal if we are to follow Burke and join those communities that are partnerships in all art, all beauty, all culture, all the virtues that ennoble life.

\section{REFERENCES}

1. Baumol, William J. and William G. Bowen. Performing Arts--The Economic Dilemma. New York: The Twentieth Century Fund, 1966.

2. Brustein, Robert. "Whither the National Arts and Humanities Endowments?", The New York Times, December 18, 1977, p. 35D.

3. Lunger, Su7,a.nne. Problems o/Art.New York: Scribners, 1957.

4. Munson, Henry Lee. "Subsidy of the Arts in Free Europe and the United States," Music Journal, January 1964, p. $46 \mathrm{ff}$.

5. National Endowment for the Arts and Humanities Annual Report 1977. Washington, D.C.: U.S. Government Printing Office, 1977.

6. "National Foundation on the Arts and Humanities Act of 1965," (Public Law 209-89th Congress), Sec. 2 (2), p. 1.

7. Panel on the Arts, Education, and America. Coming to Our Senses: The Significance of the Arts for American Educa tion. New York: McGraw Hill, 1977.

8. Public Papers of the Presidents of the United States, Lyndon B. Johnson, 1965. Washington, D.C.: United States Government Printing Office, 1966, Bk. 1, pp. 273-274.

9. Public Papers of the Presidents of the United States, Lyndon B. Johnson, 1965. Washington, D.C.: United States Govern- ment Printing Office, 1966, Bk. 1, pp. 273-274.

10. Schonberg, Harold L. "Elitism, in the Arts, Is Good," The New York Times, Feb. 5, 1978, p. 19D.

11. The Foundation Directory, 6th Ed., ed. Marianna 0. Lewis. New York: Columbia University Press, 1977, p. 323. 
12. Walker, John A. "APG: The Individual and the Organization;

A Decade of Conceptual Engineering," Studio Interna tional, March/April, 1976, pp. 162165.

13. Wellemeyer, Marilyn. "Boulevard to a Fuller Life," Fortune, October, 1977, pp. 125-146. 